\title{
PROPOSTA DE IMPLEMENTAÇÃo DE PLATAFORMA E- COMMERCE: ESTUDO DE CASO NA EMPRESA HAYANA COMERCIO DE CALÇADOS E MATERIAIS ESPORTIVOS LTDA
}

\section{ARTIGO ORIGINAL}

DUARTE, Marcelo Henrique Barros ${ }^{1}$

SANTOS FILHO, Leonardo Mendes ${ }^{2}$

LAMEGO, Thiago Pantoja ${ }^{3}$

ROBERTO, José Carlos Alves ${ }^{4}$

DUARTE, Marcelo Henrique Barros. Et al. Proposta de implementação de plataforma E-commerce: Estudo de caso na Empresa Hayana Comercio de Calçados e Materiais Esportivos LTDA. Revista Científica Multidisciplinar Núcleo do Conhecimento. Ano 05, Ed. 11, Vol. 23, pp. 14-35. Novembro de 2020. ISSN: 24480959, Link de acesso:https://www.nucleodoconhecimento.com.br/administracao/implementacaode-plataforma

\section{RESUMO}

O chamado E-commerce tem evoluído aceleradamente desde o início dos anos 2000 no Brasil. Por isso, desde lá tem sido assunto constante em reportagens sobre oportunidades de negócios divulgadas por jornais, revistas e veículos que tratam do assunto, como um dos meios mais eficientes para a administração de produtos, venda

\footnotetext{
${ }^{1}$ Graduação em Administração.

${ }^{2}$ Graduação em Administração.

${ }^{3}$ Graduação em Administração.

${ }^{4}$ Orientador. Mestre em Engenharia de Produção.
} 
e alcance de clientes de lojas criadas na internet. Com o fácil acesso à internet nos dias atuais, as empresas e indústrias estão migrando cada vez mais para o mercado virtual, a estes exemplos podemos citar a loja Bemol, Ramsons dentre outras lojas de eletrodomésticos, livrarias, etc. As plataformas digitais a partir disso tornaram-se ferramentas importantes e eficazes na venda de produtos. $\mathrm{O}$ artigo em questão visa apresentar a eficácia das estratégias que as plataformas virtuais apresentam para administrar uma empresa de calçados no mercado online, a Hayana Comércio de Calçados e Materiais Esportivos LTDA, analisando as diferentes plataformas e seus benefícios ao empreendedor. Para tanto fora realizada uma pesquisa exploratória, de caráter qualitativo e posteriormente, buscou-se dentre estas plataformas a mais utilizada nos últimos anos, para então realizar o desenvolvimento do trabalho. Os benefícios de uma loja virtual são amplos, variando de acordo com a loja virtual escolhida, sendo assim, o empresário precisa estar sempre alerta aos indicadores de sua empresa, assim mantendo seus negócios atualizados e buscando desenvolver cada vez mais sua empresa para se manter no mercado com as grandes empresas virtuais, por essa razão uma análise de plataformas torna-se necessária.

Palavras-chave: E-commerce, análise, plataformas virtuais.

\section{INTRODUÇÃO}

O comércio é uma atividade que acompanha o trabalho do ser humano há muitos séculos, não é possível indicar o período em que as atividades comerciais foram inventadas, pode-se realizar uma breve projeção sobre as primeiras trocas comerciais no período das grandes navegações. A primeira forma de comércio se deu por meio do escambo, troca de mercadorias entre pessoas. E com o tempo houve uma evolução, ainda durante o período colonial intensificaram- se as relações comerciais de tal forma que se teve a necessidade de obtenção de uma matéria "prima" de troca universal foi então a comercialização ficou mais intensa com a criação de uma moeda.

Com o passar do tempo e a diversificação, além da necessidade de alcançar a clientela o comércio foi evoluindo a fim de agregar a todos, sempre de acordo com a 
tecnologia, técnica, preços e realidade do seu principal público, e hoje é umas das atividades mais importantes para a manutenção da vida da população em geral (MENDONÇA 2016).

Existe atualmente um cenário diferente e diversificado no ramo comercial devido à facilidade ao acesso à internet e principalmente com o surgimento de várias plataformas que buscam agregar um maior número de clientes, além de expandir ainda mais os produtos de suas respectivas empresas (MÜLLER 2013). O chamado E-commerce ou comércio eletrônico, possui por conceito principal segundo Fonseca (2014) como uma combinação entre o negócio tradicional e a automatização que a internet tem permitido às empresas. Sejam nas trocas de informações, dados, realizando transações comerciais de venda de produtos, serviços, com qualidade e segurança de uma forma automática.

Devido a isso muitas estão migrando para o mercado virtual cada vez mais, a estes exemplos podemos citar a loja Bemol, dentre outras lojas de eletrodomésticos, livrarias, que se utilizam de plataformas digitais de venda para ter um maior alcance com seus produtos.

As plataformas digitais a partir disso tornaram-se ferramentas importantes e eficazes na venda de produtos e no alcance de clientes (SANTOS et al., 2014). Essa nova forma de comercialização, o chamado E-commerce tem crescido aceleradamente desde o início dos anos 2000 no Brasil (MENDES, 2013). Por isso, desde lá tem sido tema constante em reportagens sobre oportunidades de negócios divulgadas por jornais, revistas e veículos que tratam do assunto, como um dos meios mais eficientes para a administração de produtos, venda e alcance de clientes de lojas criadas na internet. $\mathrm{O}$ acesso à internet e o comportamento dos usuários é cada vez mais favorável ao crescimento do comércio eletrônico, e assim, as oportunidades de criação de lojas com um o ambiente virtual que visa proporcionar para os usuários a melhor experiência de custo/benefício nas compras além de mostrar um vasto mercado para compras (ANDRADE, 2017). 
Este artigo pretende apresentar a eficácia das estratégias que as plataformas de ecommerce apresentam para administrar e expandir a empresa Hayana Comércio de Calçados e Materiais Esportivos LTDA de maneira eficaz e com maior alcance no mercado online, avaliando as diferentes plataformas e seus benefícios ao empreendedor. De modo a indicar ainda os pontos relevantes que devem ser identificados no momento da escolha de uma plataforma virtual, benefícios, pontos negativos e dificuldades do layout que por ventura atrapalhem na expansão comercial da empresa em questão.

Os benefícios de uma loja virtual são amplos, sendo assim, o empresário precisa estar sempre alerta aos indicadores de sua empresa, buscando desenvolver cada vez mais sua empresa para crescer no mercado das grandes empresas virtuais e alcançando uma grande quantidade de clientes. Por esse motivo analisar é importante analisar e comparar os benefícios que a plataforma Shopify tem diante das outras e o que pode trazer de alcance à empresa Hayana Comércio.

O presente artigo está organizado em tópicos, dos quais este é o primeiro e apresenta o conceito geral de empreendedorismo e sua evolução no Brasil, a ampliação do Ecommerce e a adequação aos critérios do consumidor e ainda podem-se observar os objetivos e a justificativa para a realização deste trabalho. No tópico 2 é apresentado o referencial teórico sobre comércio eletrônico, plataforma de e-commerce e características apresentadas pelas mesmas. Já no tópico 3 são indicados o método e os materiais utilizados durante a elaboração do estudo, ou seja, o desenvolvimento da loja virtual, partindo primeiro da análise para posteriormente escolher a plataforma de e-commerce Uol Host.

Os resultados obtidos com o trabalho, os pontos que levaram a escolha do site estarão localizados no tópico 4 utilizando a metodologia proposta no capítulo 3, ainda no quarto capítulo encontrar-se-á uma para melhor compreensão de que forma funciona a publicidade no Instagram além de uma análise do Google ADWORDS. E por fim, no Capítulo 5 está a conclusão do estudo, bem com as considerações finais a respeito da temática. 


\section{REVISÃO BIBLIOGRÁFICA}

A revisão bibliográfica tem como objetivo abordar os principais pontos do artigo, expor a extração dos dados e apresentar diferentes pontos de vista sobre os temas abordados em artigos, revistas, livros, etc.

Segundo Chemin (2015)

A finalidade do referencial teórico, dentre outras, é destacar e resumir ideias já formuladas por outras pessoas, compará-las com autores, descrever a evolução de conhecimentos sobre o tema, mostrar contradições, tecer críticas e elogios, reafirmar comportamentos ou interpretações, salientar como a pesquisa a ser feita irá se diferenciarm assemelhar ou contribuir para o avanço do conhecimento. (CHEMIN, 2015, p. 52)

A etapa em questão aborda pesquisas e conhecimentos adquiridos através das contribuições e de desenvolvimento compartilhados de problemas que foram analisados para ser solucionados.

\subsection{EMPREENDEDORISMO}

Ao pensar no termo empreendedor, qual o primeiro conceito vem a sua mente? Se buscar no dicionário o conceito encontrado será "Indivíduo que possui capacidade para idealizar projetos, negócios ou atividades; pessoa que empreende, que decide fazer algo difícil ou trabalhoso". Apenas esse termo já é o suficiente para pensar na importância dessa ação. Ao buscar sua origem etimológica, empreendedor, originase do termo francês entrepreneur, literalmente traduzida, significa aquele que assume riscos e começa algo novo.

De modo pode-se definir como empreendedorismo a capacidade humana de inovar para superar os obstáculos que surgirem, mas essa definição envolve não apenas as pessoas que fundam empresas, mas os membros que cuidam e atuam de empresas já existentes ou ainda todas os indivíduos que mesmo sem fundarem uma empresa ou iniciarem seus negócios estão preocupados e focadas em assumir riscos e inovar continuamente, possuem o chamado espírito empreendedor.

Disponível em: https://www.nucleodoconhecimento.com.br/administracao/implementacao-deplataforma 


\subsubsection{E-COMMERCE}

As informações presentes nesse artigo têm por principal norte o e-commerce, o qual consiste em um meio de realização das antigas e transações comerciais como: compra, venda e troca de mercadorias ou serviços. Entretanto com os avanços tecnológicos as empresas passaram a ter um contato diferenciado com seus clientes através de um ambiente virtual, uma loja feita pela internet.

Também conhecido por comércio eletrônico, o E-commerce segundo Fonseca (2014) traz o seguinte conceito:

E-commerce é entendido como uma combinação entre o negócio tradicional e a automatização proporcionada pela internet, permitindo às empresas trocar informações, dados, realizar transações comerciais, entregar e vender bens e serviços de um modo automático sobre um protocolo de comunicação seguro e inovador, no qual predominantemente estarão presentes todos os potenciais compradores a nível mundial. (FONSECA, 2014, p.18)

As plataformas de e-commerce, assim denominadas no varejo eletrônico, consistem em sistemas completos com gerenciamento e visualização da loja na Web, assim como o alcance de seus produtos. Nada mais é do que sistema que possibilita criar a loja virtual e gerenciá-la, incluindo produtos, preços, estoques e demais funções que compõem o dia a dia de um comércio físico

O comércio on-line está evoluindo rapidamente e muitas empresas estão investindo nesta nova modalidade de varejo, proporcionando economia financeira e comodidade aos consumidores que utilizam a internet para pesquisar e adquirir bens e serviços, além de claro facilitar para algumas empresas que não tem a possibilidade de estocar materiais, inserindo novas empresas nessa corrente, a exemplo disso pode-se citar as lojas on-line de impressão em demanda que facilitam a vida de seus clientes imprimindo e enviando o camisas, canecas, após as escolhas em sua plataforma.

$\mathrm{O}$ E-commerce permite que empresas comercializem seus produtos e serviços aos seus consumidores através de plataformas na internet, dessa forma são capazes de 
alcançar ainda mais clientes devido ao alcance de impulsionamento que é possível ser feito dos produtos nas redes sociais, sem que estes saiam de casa para fazer propagandas visuais, panfletagem.

Com tantas lojas disponíveis no mercado o e-consumidor torna-se um cliente exigente, que busca atingir suas expectativas em sua compra on-line, seja no conforto de sua casa, ou onde quer que esteja. Diante desse pressuposto, para que as empresas virtuais consigam a fidelidade de seus e-consumidores e obtenham sucesso de vendas é fundamental seguir alguns requisitos básicos de desempenho do ecommerce, devido a ampla concorrência desse shopping a um "click" de distância.

A satisfação do cliente deve ser o principal objetivo de toda empresa no comércio online, buscando conquistar novos clientes e fidelizar os já existentes. Conforme Mansano e Gorni (2014) a grande preocupação das empresas sempre foi a satisfação do cliente, pois o cliente satisfeito e fiel é o passo para o sucesso e permanência na compra de produtos de uma empresa. Ou seja, a experiência na compra de produtos será um divisor de águas no processo de crescimento das empresas desse meio. Além do processo de aquisição do produto ou serviço é de suma importância cativar o cliente, seja com o melhor atendimento, frete grátis, ou mesmo brindes pela compra.

Trata-se da satisfação advinda da qualidade do serviço no processo como um todo, desde o layout da loja virtual, até a facilidade na hora de mexer no site, até a escolha do produto, efetivação da compra, para a posterior entrega do produto. Assim nota-se ser de suma importância identificar o nível de satisfação presente nos fatores de desempenho de uma compra na plataforma, ou seja, os requisitos considerados pelos empreendedores da HAYANA COMÉRCIO DE CALÇADOS E MATERIAIS ESPORTIVOS LTDA.

O comércio online então se trata da evolução do que é conhecido por "negócio". As atividades envolvidas em tal definição recebem um novo tratamento que consiste na criação de novas possibilidades introduzidas pela internet. Nesse contexto surge uma nova maneira de se efetuar trocas, emissões de dados e informações, assim como a negociação de bens e serviços. Desta maneira se tem a tecnologia como valor

Disponível em: https://www.nucleodoconhecimento.com.br/administracao/implementacao-deplataforma 
agregado às formas tradicionais de atividades de negócios, porém tendo por ferramenta o recurso da automação tecnológica e assim com um alcance espacial em larga escala, na internet o alcance do produto e da marca vai muito longe.

Para obter um bom alcance entre os consumidores é necessário então apresentar uma plataforma de fácil acesso, sem dificultar a movimentação do cliente em seu layout, além é claro das possibilidades de pagamento adequadas às necessidades de cada um, esses são alguns pontos primordiais na hora de observar a plataforma de E-commerce mais adequado, caso contrário o objetivo de alcançar de forma mais rápida o cliente pode não ser realizada, e acabar prejudicando as vendas da empresa.

\subsubsection{ANÁLISE DE MERCADO}

No cenário atual de E-commerce temos um leque de serviços realizados por empresas, seja na realização da compra de produtos até na terceirização de serviços de gráficas, por exemplo. A Amazon iniciou esse processo de vendas onlines que atualmente conta com várias empresas que trazem uma proposta similar de vendas de produtos.

Partindo desse princípio a empresa HAYANA COMÉRCIO DE CALÇADOS E MATERIAIS ESPORTIVOS LTDA está buscando ingressar no mercado usando uma das plataformas de E-commerce, para se igualar as tantas empresas que vendem calçados online.

Para a escolha de uma plataforma que a empresa usará será necessário seguir alguns pontos devem ser, pois podem determinar o sucesso ou não da empresa no comércio digital.

Foram escolhidos os seguintes aspectos, que precisam ser avaliados durante a análise das plataformas de acordo com as necessidades dos clientes:

- Atualização conforme necessidade cliente;

- Facilidade de utilização do módulo de gerenciamento; 
- Sites que adaptam o layout de acordo com o dispositivo utilizado.

- Flexibilidade com integração com outras tecnologias, tais como meios de pagamento, atendimento via chat, bancos e etc.;

- Controle do título das páginas.

- Design responsivo para dispositivos móveis

- Layout de fácil acesso na localização de informações

\section{MATERIAIS E MÉTODOS}

Metodologia é o estudo dos métodos ou dos instrumentos necessários para a elaboração de um trabalho científico, abordando as principais regras para uma produção científica e objetiva para um melhor desempenho e qualidade de um trabalho científico.

Segundo Gobbi et al (2012, p.13) "Metodologia de pesquisa é definição sobre como será executada a pesquisa e o modelo metodológico a ser adotado." Deste modo este trabalho utilizará métodos que auxiliam a identificar a proposta mais adequada para aplicar de acordo com as necessidades da empresa Hayana Comércio de Calçados e Materiais esportivos LTDA.

\subsection{PROCEDIMENTOS METODOLÓGICOS}

Os procedimentos metodológicos representam a escolha do método, bem como o instrumento a ser utilizado. Este trabalho se realizou por meio da coleta de informações e dados, tendo como objetivo identificar os processos implementação, aplicar o uso da tecnologia das plataformas virtuais para auxiliar no desempenho da gestão, do marketing e de vendas da empresa analisada.

\subsubsection{QUANTO À NATUREZA}

Segundo Kinchescki et al (2015) a natureza da pesquisa científica pode se apresentar de diferentes maneiras cada uma com suas especificidades e de acordo com sua finalidade podendo ser definidas como pesquisa básica ou aplicada. A natureza da 
pesquisa utilizada no projeto é aplicativa, pois possui a finalidade de resolver os problemas encontrados na empresa que foi selecionada com a aplicação de ferramentas tecnológicas que auxiliam no engajamento das vendas da empresa no ambiente virtual. A abordagem é qualitativa, pois propõe uma análise de dados através da coleta de informações por meio da Plataforma Uol Host.

\subsubsection{QUANTO AOS FINS}

A pesquisa descritiva é aquela que através das buscas de características define determinado fenômeno e estabelece relações com as variáveis, ou seja, este tipo de pesquisa exige que seja feito um levantamento de informações sobre o objeto de estudo da maneira mais detalhada possível. Quanto aos fins, no projeto foi utilizado a abordagem de estudo de caso que segundo Pereira et al (2018, p. 65) "é uma descrição e análise de algum caso que apresente alguma particularidade".

\subsubsection{QUANTO AOS MEIOS}

A pesquisa quanto aos meios se fundamenta em descrever um problema utilizando todos os recursos disponíveis buscando embazamento teórico de livros ou artigos publicados (KÖCHE, 2015). O projeto foi baseado em pesquisa de campo, pois foi realizada uma observação da empresa, coleta dos dados encontrados, análise descritiva e interpretação das variáveis a fim de juntar informações que servirão de base pra uma solução das problemáticas.

\subsection{CARATERÍSTICAS DA EMPRESA}

A empresa Hayana Comércio de Calçados e Materiais Esportivos, localizada na Rua Leovegildo Coelho, 96, bairro Centro da Cidade de Manaus - AM. A empresa tem um ótimo espaço tanto o salão de vendas quanto o estoque. Imaginando que a empresa alcançará clientes que com o limite físico não se tornariam compradores de sua loja. Além de fornecer soluções a pessoas interessadas em seu produto, o negócio alcançará muito mais clientes potenciais. 
Por ser uma loja que fica localizada no centro da cidade de Manaus, próximo à "Feira da Capital Amazonense", os proprietários não pensam em mudar de localização, sendo que há um fluxo razoável de vendas. Sendo assim um dos motivos para a criação da plataforma e-commerce, sendo uma oportunidade de ampliar o alcance do negócio e subir o nível competitivo no mercado.

\section{RESULTADOS E DISCUSSÕES}

Com base no estudo de caso da empresa Hayana, observamos que a empresa tem um bom desenvolvimento na parte de vendas, logística. Porém na área do marketing a empresa deixa à desejar. Conforme a análise realizada, levantamos pontos de grande importância para a implementação do e-commerce para estabelecer o alcance dos objetivos e fazer com que a empresa venha competir com grandes lojas virtuais no mercado.

\subsection{PLANEJAMENTO DE AÇÕES}

O planejamento de ações representa o quadro de ação ou mudanças que serão inseridas dentro do ambiente interno para que obtenha assim uma estratégia definida para alcançar os objetivos do trabalho.

Quadro 01: Ações interventivas.

\begin{tabular}{|c|c|c|c|c|}
\hline Item & Ação interventiva & Procedente & Cronologia & Custo \\
\hline 1. & $\begin{array}{l}\text { Treinamento para a } \\
\text { padronização dos } \\
\text { processos. }\end{array}$ & $\begin{array}{l}\text { Falta de padronização } \\
\text { nos processos. }\end{array}$ & Dois dias. & $\mathrm{R} \$ 1.500,00$ \\
\hline 2. & $\begin{array}{l}\text { Implementação da } \\
\text { plataforma virtual e } \\
\text { mapeamento dos } \\
\text { processos on-line. }\end{array}$ & Falta de treinamento. & Dois Dias. & $\mathrm{R} \$ 800,00$ \\
\hline
\end{tabular}




\begin{tabular}{|l|l|l|l|l|}
\hline 3. & $\begin{array}{l}\text { Implementação do } \\
\text { material de apoio para } \\
\text { o trabalho remoto. }\end{array}$ & $\begin{array}{l}\text { Falta computadores e } \\
\text { boa conexão de } \\
\text { internet para atuar } \\
\text { virtualmente }\end{array}$ & Um dia. & R $\$ 5.000,00$ \\
\hline 4. & $\begin{array}{l}\text { Implementação das } \\
\text { ferramentas ADS }\end{array}$ & Falta de marketing. & Três dias. & $\mathrm{R} \$ 800,00$ \\
\hline Total & & & $\mathbf{R} \mathbf{8 . 1 0 0 , 0 0}$ \\
\hline
\end{tabular}

Fonte: Elaborado pelos autores, 2020.

A proposta do artigo se desenvolveu por meio da ferramenta $5 \mathrm{w} 2 \mathrm{~h}$, onde se trata de uma ferramenta da qualidade utilizada para identificar as principais perguntas para se implementar uma estratégia.

Para Custodio (2015, p. 32). "A técnica 5W2H consiste em um plano de ação organizado e simples, que encaminha a solução dos problemas, ordenando de forma prática a tomada de ações, identificando os principais elementos a serem abordados".

\subsubsection{TREINAMENTO PARA A PADRONIZAÇÃO DOS PROCESSOS}

Para realizar a o treinamento e padronização dos processos, é necessário que todos os colaboradores e gestores possam conhecer cada procedimento, todos os processos realizados até a finalização da venda e pós-venda. Para poder obter maior qualidade e eficiência, principalmente se tratando de um novo modelo de negócio para a empresa em questão.

Quadro 02: 5w2h - Treinamento para a padronização dos processos.

Treinamento para a padronização dos processos

O que? Treinamento dos colaboradores. 
Por quê? Para padronizar os métodos de logística da loja virtual.

Onde? Na empresa Hayana Comércio.

Quando? Primeira semana de outubro de 2020.

Quem? Departamento de vendas e departamento de logística.

Através de uma reunião com todos os colaboradores para aplicar o

Como? treinamento oferecido para padrozinar o novo modelo de empresa.

Quanto? $\quad \mathrm{R} \$ 1.500,00$

Fonte: Elaborado pelos autores, 2020.

\subsubsection{IMPLEMENTAÇÃO DA PLATAFORMA VIRTUAL E MAPEAMENTO DOS PROCESSOS ON-LINE}

O bom desenvolvimento desta etapa é de grande importância para que nao ocorra erro na hora de realizar os cadastros, configurações da plataforma, configuração dos meios de pagamento, transportadoras e tudo que o e-commerce precisa para vender e entregar.

Além de compreender o passo a passo da natureza e o fluxo deste processo. Com o objetivo de mostrar de forma descomplicada o fluxo das informações, evidenciando a sequência operacional que caracteriza o trabalho que está sendo executado.

Quadro 03: 5w2h - Implementação da plataforma virtual e mapeamento dos processos on-line.

Implementação da plataforma virtual e mapeamento dos processos on-line.

O que? Implementação da plataforma e-commerce

Por quê? Para poder atuar no mercado virtual.

Onde? Na empresa Hayana Comércio.

Quando? Primeira semana de outubro de 2020.

Quem? Todo departamento da empresa Hayana. 
Como? Por meio da hospedagem em uma plataforma virtual.

Quanto? $\mathrm{R} \$ 800,00$

Fonte: Elaborado pelos autores, 2020.

\subsubsection{IMPLEMENTAÇÃO DO MATERIAL DE APOIO PARA O TRABALHO REMOTO}

Assim como o colaborador se sente mais disposto à produzir em um bom ambiente de trabalho, no e-commerce é da mesma forma. Um bom computador e uma internet mais rápida é de grande importância para o melhor desempenho do colaborador e da organização.

A partir desse ponto, o mercado é proposto à passar por uma profunda transformação e têm que se adaptar a elas da forma mais lucrativa e inovadora possível, de forma a se tornar referência em sua área de atuação.

Quadro 04: 5w2h - Implementação do material de apoio para o trabalho remoto

Implementação de material para atuar on-line.

O que? Aquisição de material de escritório

Por quê? Para os funcionários trabalhar na plataforma on-line.

Onde? Na empresa Hayana Comércio.

Quando? Primeira semana de outubro de 2020

Quem? Departamento de logística e departamento financeiro.

Mediante os orçamentos do material como computadores, mouse e

Como? internet para inserir no espaço interno da empresa para melhor

Quanto? $\quad \mathrm{R} \$ 5.000,00$

Fonte: Elaborado pelos autores, 2020.

\subsubsection{IMPLEMENTAÇÃO DAS FERRAMENTAS ADS}

Disponível em: https://www.nucleodoconhecimento.com.br/administracao/implementacao-deplataforma 
Espera-se através da plataforma ADS que tenha maior visualização da empresa e maior engajamento da página no espaço virtual.

Além de alcançar viewers, teremos controle de quantos cliques e quantas visualizações a empresa obteve, através desta ferramenta.

Com esta ferramenta se visa o próprio relatório de desenvolvimento da empresa no espaço virtual e que ela funcione como uma ferramenta de qualidade da empresa, apresentando resultados do próprio marketing e outras áreas dentro da plataforma.

Quadro 05: 5w2h - Implementação das ferramentas ADS

Implementação das ferramentas ADS

O que? Inserção da empresa na área de anúncios.

Por quê? Para divulgar a empresa e seus produtos nas páginas da internet.

Onde? No a plataforma virtual da empresa Hayana.

Quando? Primeira semana de outubro de 2020.

Quem? Setor de marketing da empresa.

Como? Por meio da implementação de divulgação em todas as redes sociais mais relevantes e através do google adwords

Quanto? $\quad \mathrm{R} \$ 800,00$

Fonte: Elaborado pelos autores, 2020

\section{ESCOLHA DA PLATAFORMA A SER UTILIZADA}

Para a escolha da plataforma a ser utilizada fora observado alguns pontos do site Ecommercebrasil para ter como embasamento na escolha da plataforma. De acordo com o site E-commerce Brasil para escolher sua platual capital algumas questões devem ser consideradas:

1. Qual capital você tem para investir na plataforma?

2. Histórico da empresa que fornece a plataforma, produtos. 
- Estudar outras empresas/e-commerce que utilizam a plataforma

1. Tem integração com alguma ferramenta de analytics?

2. Oferece relatórios de gestão da página? E como esses relatórios são?

3. Quais as formas de pagamento a plataforma permite? Você tem liberdade para escolher/implementar isso?

- Quais ferramentas de segurança a plataforma oferece?

- Sua plataforma oferece suporte via e-mail e telefone? Quem é o responsável por te ajudar em caso de falhas?

1. Quais são as funcionalidades oferecidas pelas empresas do mesmo segmento que o seu? Caso você queira, a sua plataforma terá a capacidade de oferecer as mesmas funcionalidades?

2. Será possível expandir/alterar a plataforma a curto ou médio prazo? Qual seria o custo dessa expansão? Quem será o responsável por alterar, você ou a própria plataforma?

Abaixo segue uma tabela com as características de cada plataforma escolhida.

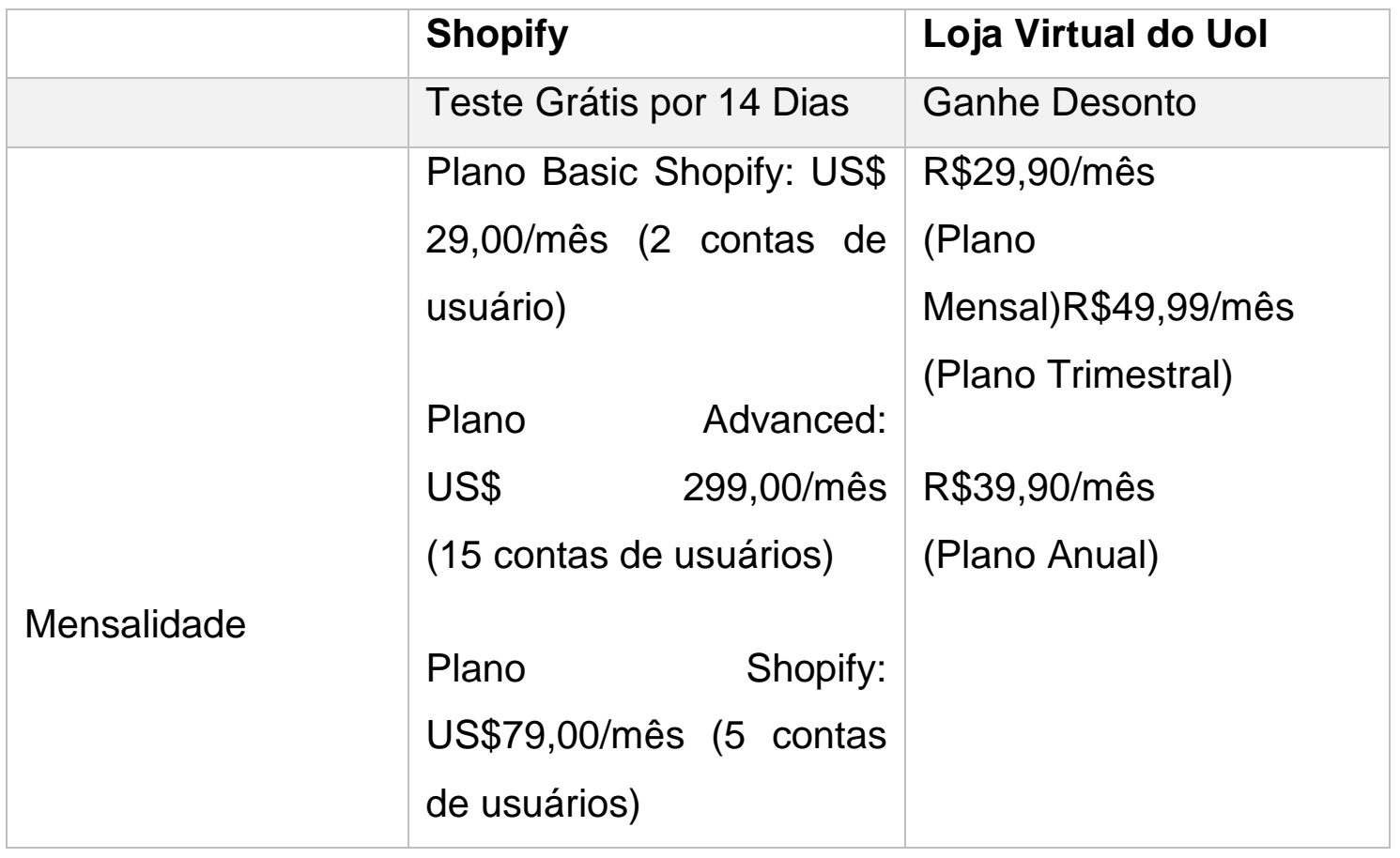




\begin{tabular}{|c|c|c|}
\hline & $\begin{array}{l}\text { Pessoa física ou pessoa } \\
\text { jurídica }\end{array}$ & $\begin{array}{l}\text { Pessoa física ou pessoa } \\
\text { jurídica }\end{array}$ \\
\hline Taxa de transação & $\begin{array}{l}\text { Plano Shopify: } 1 \% \text { por } \\
\text { venda } \\
\text { Plano Basic Shopify: } 2 \% \\
\text { por venda } \\
\text { Plano Advanced: } 0,5 \% \text { por } \\
\text { venda }\end{array}$ & Não há \\
\hline $\begin{array}{l}\text { Moeda da } \\
\text { mensalidade }\end{array}$ & Dólar & Real \\
\hline Mensalidade via & Cartão de crédito & $\begin{array}{l}\text { Cartão de crédito ou } \\
\text { boleto }\end{array}$ \\
\hline Idioma da plataforma & Parcialmente em inglês & Português \\
\hline Checkout & $\begin{array}{l}\text { BitPay, } 2 \text { Checkout, } \\
\text { Coinbase } \\
\text { ComproPago, } \\
\text { Paypal, Mercado Pagrill, } \\
\begin{array}{l}\text { PagBrasil, } \\
\text { GoCoin, CyberSource, }\end{array} \\
\text { PayU Latam, Put It On } \\
\text { Lay-Buy }\end{array}$ & Pag Seguro \\
\hline
\end{tabular}

Fonte: Elaborado pelos autores, 2020

Para escolher a plataforma foram observados os itens acima para selecionar a plataforma para a empresa.

\subsection{PLATAFORMA SHOPIFY}

A plataforma Shopify tem a possibilidade de enviar produtos para todo o Brasil e de acordo com os planos, até para outros países. Ela oferece relatórios de gerenciamento 
da página, dá suporte no caso de problemas, entretanto sua forma de pagamento dos planos é em dólar e no cartão de crédito, além de ser retirada uma tarifa por produto vendido, além de pagar o plano mensal. O que acaba saindo mais caro ao cliente e ao empreendedor.

\subsubsection{PLATAFORMA UOL HOST}

Apesar das propostas do Uol host estarem abaixo do valor do Shopify, as propostas do Uol são bem diferentes de acordo com a quantidade de itens e contas de e-mails personalizados que você pode registrar, e os planos da Shopify quanto ao número de contas de usuários e aplicações extras. Assim, ao realizar uma comparação entre eles é um pouco mais difícil. Apesar disso, o preço do Shopify é de qualquer modo maior do que o da Uol host por conta da arrecadação em dólar e a fragilidade do real em relação à moeda americana

\subsubsection{ESCOLHA FINAL DA PLATAFORMA}

A plataforma escolhida diante dos pressupostos foi a Plataforma UOL HOST, para os novos empreendimentos é a melhor alternativa, embora a plataforma Shopify seja mais completa, o custo mais baixo, a mensalidade em moeda nacional, a plataforma em português e o fato de não necessitar de cartão de crédito para criar uma loja, torna o UOL HOST o mais adequado às necessidades da empresa Hayana,

\subsubsection{PUBLICIDADE NO INSTAGRAM}

De acordo com o site Bluberry, o Instagram Ads é um dos mecanismos com maior repercussão na Internet, onde mais de 400 milhões de clientes estão presentes, sendo desse total em torno de $8 \%$ de brasileiros, com impressionante participação. Neste contexto, podemos imaginar que essa rede pode ser uma ótima oportunidade para investimento. É a segunda rede social mais acessada no Brasil, perdendo apenas para o Facebook. 
Esta rede é composta por vários recursos que podem ser muito bem utilizados, reassaltando assim os anúncios que são capazes proporcionar um ótimo poder de segmentação aos seus anunciantes. Permitindo, assim, a realização do direcionamento de acordo com os parâmetros estabelecidos pelo Facebook. Geralmente, os anúncios dividem-se por:

- Interesses de consumo;

- Públicos especiais (lista de contatos, quem acessou o seu site, etc.)

- Sistemas de acesso e dispositivos;

- Localização geográfica (como país, estado e cidade, por exemplo);

- Sexo;

- Faixa etária;

- Principais interesses (como esportes, cinema, tecnologia, música, etc.);

- Situações da vida (casado, inserido no mercado de trabalho, já formado, etc.);

Abaixo segue uma tabela de acordo com o objetivo na busca por anúncios.

Tabela 1: Anúncios no Instagram

\begin{tabular}{|l|l|}
\hline Tipo de anúncio & Característica \\
\hline Carrossel & Anúncio com duas ou mais fotos e/ou vídeos \\
\hline Imagem única & Anúncio com apenas uma foto \\
\hline Vídeo único & Anúncio com apenas um vídeo \\
\hline $\begin{array}{l}\text { Apresentação } \\
\text { multimídia }\end{array}$ & $\begin{array}{l}\text { Anúncio com um conjunto de imagens que possuem tempo de } \\
\text { exibição definido }\end{array}$ \\
\hline Espécie de vitrine, para empresas que desejam vender os \\
poleção & \begin{tabular}{l} 
produtos diretamente pelo Instagram \\
\hline
\end{tabular} \\
\hline
\end{tabular}

Fonte: Instagram (2019)

\subsubsection{GOOGLE ADWORDS}


Com sua primeira versão lançada em 2000 pela gigante californiana Google, o Google Ads, novo nome da plataforma, é uma ferramenta de publicidade on-line que exibe anúncios em forma de links patrocinados assim que uma pessoa realiza uma busca, baseando seus resultados nas palavras-chave usadas no momento da pesquisa.

A plataforma do Google, mesmo com o surgimento de várias outras no mercado como a do Facebook, ainda lidera o ranking mundial de receita com publicidade on-line, com incríveis U\$ 134 bilhões de dólares apenas em 2019 com base em dados do Statista. Hoje é uma das ferramentas de anúncio que mais gera retorno para as empresas, é também uma opção muito interessante para os e-commerces investirem Google Ads e verificar o alcance de seus produtos.

\subsubsection{PLANO FINANCEIRO DA PLATAFORMA ESCOLHIDA}

O cadastro na plataforma pode ser realizado tanto por pessoa física quanto por pessoa jurídica para contratar qualquer um desses recursos, então não há problemas nesse ponto. Logo ao criar o cadastro o Uol traz duas vantagens, o pagamento pelo serviço pode ser realizado no boleto bancário e a cobrança é real. Deste modo se a pessoa não houver cartão de crédito e não sofrerá qualquer cobrança em real ou moeda estrangeira. Os valores dos planos $\mathrm{R} \$ 29,90$, Plano Mensal, $\mathrm{R} \$ 49,99$ no Plano Trimestral e $\mathrm{R} \$ 39,90^{*} /$ mês no plano anual. O plano escolhido pela empresa foi o mensal. Importante frisar que independente do plano pago a empresa tem acesso a todos os benefícios.

\section{CONSIDERAÇÕES FINAIS}

O artigo em questão teve como objetivo principal mapear os principais desafios que uma empresa tem para abrir uma loja virtual usando a empresa Hayana Comércio de Calçados e Materiais Esportivos LTDA. Cada plataforma tem características, benefícios que facilitariam a criação de lojas virtuais, mas esbarra em alguns pontos, como a necessidade de vincular cartão de crédito para pagar os planos mensais de hospedagem nos sites, além é claro, do fato da maioria das plataformas cobrarem seus planos em moedas estrangeiras, dólar, euro e no momento que o país vive de

Disponível em: https://www.nucleodoconhecimento.com.br/administracao/implementacao-deplataforma 
desvalorização da moeda no mercado, não é lucrativo investir em algumas delas. Embora através da internet tornou-se mais fácil a alcançar clientes, fazer o controle de estoque que muitas plataformas disponibilizam.

Nesse contexto, o comércio virtual mostra-se como uma opção promissora e eficaz se o empreendedor souber aproveitar as possibilidades de vincular suas marcas às redes sociais e usá-las como forma de alavancar seu mercado.

Nesse sentido, o trabalho conseguiu avaliar quais seriam os desafios das empresas ao criar sua loja virtual, quais os empecilhos que existem devido algumas questões burocráticas comuns às lojas virtuais, através de uma análise de duas plataformas virtuais bastante usadas atualmente. Foi validado então que os principais desafios consistiam em questões envolvendo a fidelização com o site, pois a maioria obriga o uso do cartão de crédito, além disso, tem o valor do frete no envio de produtos, além da demora para chegar, existe um alto custo por serviços mais rápidos de entrega, a parte boa no quesito plataformas é a questão da visibilidade que é agregada ao crescimento da divulgação de produtos via redes social.

\section{REFERÊNCIAS}

ANDRADE Marta Cleia Ferreira, SILVA Naiara Taiz Gonçalves. O COMÉRCIO ELETRÔNICO (E-COMMERCE): um estudo com consumidores. Perspectivas em Gestão \& Conhecimento, João Pessoa, v. 7, n. 1, p. 98-111, jan./jun. 2017

CHEMIN, B. F. Manual das Univates para trabalhos acadêmicos: planejamento, elaboração e apresentação, 3ํe ed. Lajeado: Ed. da Univates, 2015.

CUSTODIO, Marcos Franqui. Gestão da qualidade e produtividade. São Paulo: Pearson Education do Brasil, 2015.

FONSECA, Luís Filipe Matos. Riscos Percebidos pelos Consumidores Portugueses nas Compras Online. IPAM: The Marketing School. Escola Superior de Aveiro. Outubro, 2014. 
GOBBI, Beatriz Christo. Manual de Monografia ESAB 2012 / Escola Superior Aberta do Brasil - Vila Velha, ES, 2012. Disponível em <https://silo.tips/download/escolasuperior-aberta-do-brasil-esab-manual-de-monografia>. Acesso em: 15 set. 2020

INSTAGRAM. Desenvolva seu negócio no Instagram. Disponível em: $<$ https://business.instagram.com/advertising?locale=pt_BR >. Acesso em: 08 out. 2020.

KINCHESCKI Geovana Fritzen; ALVES Rosangela; FERNANDES Tânia Regina Tavares. Tipos de metodologias adotadas nas dissertações do programa de pósgraduação em administração universitária da Universidade federal de santa catarina, no período de 2012 a 2014. Universidade federal de Santa Catarina, 2015.

KOCHË José. Fundamentos de metodologia científica: teoria da ciência e iniciação à pesquisa. 34. ed. Petrópolis, RJ: Vozes, 2015.

MANSANO, Adriana Toledo Rodrigues; GORNI, Patrícia Monteiro. Satisfação do consumidor com o comércio eletrônico: estudo de caso de uma fabricante de tapetes. Revista de Extensão e Iniciação Científica SOCIESC - REIS, Santa Catarina, v. 1, n. 1, p.12-22, jun. 2014.

MENDES, Laura Zimmermann. E-commerce: origem, desenvolvimento e perspectivas. Universidade Federal do Rio Grande do Sul, 2013.

MENDONÇA, Herbert Garcia. E-commerce. Journal of Innovation, Projects and Technologies - JIPT. Revista Inovação, Projetos e Tecnologias - IPTEC. Vol. 4, N. 2. Jul./ Dez. 2016

MÜLLER Vilma Nilda. E-commerce: vendas pela internet. Fundação Educacional do Município de Assis - FEMA - Assis, 2013

PEREIRA Adriana Soares, SHITSUKA Dorlivete Moreira, PARREIRA Fabio José, SHITSUKA Ricardo. Metodologia da pesquisa científica. Universidade Federal de Santa Maria, UAB/NTE/UFSM. Santa Maria, 2018. 
SANTOS João Batista, KUNZ Marinês Andrea. Estratégias de marketing em plataformas digitais. Revista de Administração; v. 12, n. 21, p. 73-92, Ago. 2014.

Enviado: Outubro, 2020.

Aprovado: Novembro, 2020. 